\title{
Inferior Sagittal Sinus
}

National Cancer Institute

\section{Source}

National Cancer Institute. Inferior Sagittal Sinus. NCI Thesaurus. Code C12514.

An intracranial venous sinus that lies in a midline location along the lower free border of the falx cerebri of the brain. The sinus receives blood from the great cerebral vein and joins the superior sagittal sinus posteriorly. 